\title{
The Pragmatic Impact of Background Emotional Memory on Interpersonal Relations
}

\author{
Shushanik Paronyan, Anna Rostomyan \\ Yerevan State University
}

$\mathrm{O}$ ur human nature incorporates a rich variety of factors which shape our behaviour in general. Being a specific form of social behaviour, speech is based on a number of essential features forming the general framework of the communicative context. The aim of the present paper is to discuss one of the ingredients of the communicative context - the speakers' mental world. We will try to reveal the intrinsic value of this essential component in the process of communication. We strongly believe that a large part of implicit meaning which remains unsaid and veiled in the process of interaction is related to human emotions and feelings. The speakers' past emotional experience is also part of mutually shared background knowledge which determines the choice of language data on a particular occasion of speech event. To ensure a better understanding of the multifaceted nature of emotions, the problem is being viewed from the pragmatic perspective, taking into account the essence of the supreme cognitive processes.

In general, human communication is designed to create an effect of mutual understanding and respect of self and other. It aims at building a unified, tolerant society and establishing peaceful relations among the members of the given speaking community. Thus, speakers usually have a natural propensity to communicate amicably with each other unless there is some reason (objective or subjective) for them to spoil the harmonious public relations in which case they tend to disagree, argue, dispute, quarrel, debate and so on. Further, it is generally known that communication relies mainly on the interpretive power of speakers. This is the reason why a large portion of information is being conveyed in the process of verbal interaction implicitly, without saying it openly. Much has been said so far about aspects of implicit meaning in pragmatics (Searle 1969; Grice 1975; Verschueren 1999; van Dijk 1977). Research carried out in this field of analysis comes to prove that speakers usually exercise their interpretive power to decode the illocutionary force of the speech act (direct or indirect). They guess the implicature hidden in the message, grasp the effect of irony or sarcasm in speech, fit certain background knowledge to chunks of informative patterns in speech in order to decode certain information properly, recognize the clichéd behavioural frames and practice the scenarios stored in the long-term memory in order to decode the strategic involvement of the particular speech event, and so on. In the present paper we shall focus on one of the aspects of implicit meaning which has not been discussed much yet - the role of background emotional memory in the process of verbal interaction. We shall try to reveal the pragmatic impact of emotions on verbal behaviour and show its implicit effect on interpersonal relations of the speaking partners.

Our everyday life consists in chains of interactions with different speaking partners. We do this via verbal and non-verbal means such as facial expressions, gestures, gross bodily movements. It goes without saying that if we want to build a successful society, 
we should establish peaceful relations with one another, and, therefore, it is important for us not to misinterpret any piece of information encoded by our speaking partners. As a matter of fact, it often becomes a real challenge to grasp the implicit meaning, the hidden thoughts and intentions of the speaker which are actually not always so vividly expressed in speech. In many cases it is the communicative information shared by the speakers that makes mutual understanding possible in the act of verbal interaction.

It should be stated that the philosophers and social scientists have already attempted to evaluate the significance of background knowledge in the process of social interactions. David Hume (2001) was perhaps the first to make explicit reference to the role of mutual knowledge in coordination and cooperation. In his account of convention in "A Treatise of Human Nature", Hume argued that a necessary condition for coordinated activity is that all agents know what behaviour to expect from one another. Without the requisite mutual knowledge, Hume maintained, mutually beneficial social conventions would disappear. The analyses and applications of common knowledge and related multiagent knowledge concepts are a lively field of research (Brandenburger, Dekel 1987; Gilbert 1989).

Despite the fact that a lot of research work has been done in this field of study, there are many questions that still require clarification and thorough research. As such, we do believe that in order to unveil the subconscious aspect of the influence of human mind on speech, which is usually "hidden" from the reader's/interpreter's eye, it is necessary to view background knowledge from the angle of human emotivity. For this purpose let us illustrate how the emotional components of background knowledge get stamped in the speaker's memory and influence his/her higher cognitive processes.

The term emotional memory was introduced into cognitive linguistics long ago (Murray 1964). This term comes to prove how two important aspects of human mind emotion and memory - are interrelated. In previous works on the cognitive-pragmatic aspect of discursive behaviour, we have tried to prove that memory forms an essential part of the situational context. It provides a reliable basis for the successful operation of the components of background knowledge. Background knowledge (also called common knowledge, mutual knowledge) refers to various aspects of the communicative context the physical world or the immediate environment in which communication is maintained, the social world or the social factors of the interlocutors (age, status, intimacy, etc.) and, finally, the mental world. We have also noted that the aspect of background knowledge which belongs to the mental world contains both cognitive and emotional elements (Paronyan 2005; 2009; 2011; Paronyan, Rostomyan 2011). Hence, the mental world contains chunks of knowledge of the objective world which are stored in the memory in the form of scenarios and strategic frames.

Furthermore, the mental world is connected with human psychology, that is, it depends to a certain extent on the psychological state of the speaking partners - the emotional experiences, expectations, intentions and dispositions they have in the process of communication. It should be mentioned that the problem concerning the interrelation between the cognitive and emotive elements of mind has been a matter of lively debates in philosophy for a long time, and is still open to discussion. Thus, Lock distinguishes 
between sensation and reflection (Locke 1969), while Jaggar talks about the relation between knowledge and emotion (Jaggar 1989).

The indexicals of the psychological state of the interlocutors predetermine the emotive charge of speech (both explicit and implicit); they convey emotional effect to speech, exercise emotional and logical influence on the listener and, at the same time, form basis for the hearer to interpret the speech emotionally. Hence, emotional memory works both for the speaker who encodes certain emotive meaning into his/her speech and the hearer who decodes the speaker's intended meaning emotively. Thus, we assume that a large part of implicit meaning which remains unsaid and veiled in the process of interaction is related to human emotions and feelings. The speakers' past emotional experience, which, as we said, is also part of mutually shared background knowledge, determines the choice of language data on a particular occasion of a speech event. Hence, being components of the speaker's mental world, feelings and emotions often find their outward verbal or nonverbal manifestation in speech, especially when the speaker does not manage to suppress a particular emotion or when he/she wants to have an emotive impact on the hearer.

As a matter of fact, a great deal of research work has also been done in linguistics to define the linguistic devices which give an evaluative impact to speech - words, wordcombinations, constructions, speech acts which are bearers of certain emotional attitude (positive or negative). In fact, the problem of emotion involves a number of important aspects: perception of emotions, processing and evaluation of emotional states; verbal and non-verbal means of expressing emotion. Facial expressions, together with bodily movements form the non-verbal means of communicating the emotional state of the speaker. As for the verbalization of emotions, there exist certain function words called intensifiers which are used to modify the emotional content of certain words, or intensify the whole utterance or only part of it (Buzarov 1998, Rostomyan 2009). The analysis of the factual material has enabled us to claim that the manifestation of emotions in the process of verbal interaction is more vivid in expressive speech acts, verbal actions whose communicative purport is to state what the speaker feels.

It is well known that emotions are grouped into two main opposite groups according to evaluation - positive emotions (such as love, affection, happiness, etc.) and negative emotions (such as hatred, anger, rage, etc.). These emotions can be highlighted in the process of interaction by using certain intensifiers. In the following example we find intense manifestation of the positive emotional state of the speaker:

"I know what you mean," said Anne Elizabeth, ruffling up his hair. "You're an artist, Dick, and I love you very much ... you're my poet, Dick."

$$
\text { (D.P., "U.S.A.": 325) }
$$

In this passage Anne Elizabeth expresses love, caring, tenderness towards her beloved person. To give emotive emphasis to the expressive speech act and reach an amplified positive emotive impact on the interlocutor, she uses the intensifying adverb very much. Ann Elizabeth's affection towards Dick, their intimacy is also communicated non-verbally, by ruffling up Nick's hair. 
In the next example the emotional speech of the speakers reveals their negative emotional mind:

"O God, I feel sick," said Bill Grey, taking the cigarette out of his mouth and looking at it revengefully.

"I'd be all right if everything didn't stink so. An' that mess hall. Nearly makes a guy puke to think of it."

(D.P., Th. S.:43)

The soldiers, as we may imagine, are in misery and desolation: the first soldier expresses his anger by expressing complaint and gesturing with his cigarette. The second one also makes a complaint: the intensifying adverb so places an extra negative emotive emphasis on the verb didn't stink, amplifying its negative connotative meaning. Anyhow, he does not want to strain the atmosphere and tries to hedge the negative impact with the help of the approximator nearly which modifies the verb makes. Evidently, we deal with a case of negative evaluative statement bearing unfavourable implicature.

There are also non-verbal markers of emotions, such as bodily postures, gestures, facial expressions, and the like. Sometimes even just one gaze may be sufficient enough to decode the intended emotive meaning - whether positive or negative:

Dan Ford caught Scott's eye; his ex-senior partner's expression asked a silent question: You gave up your career for a murderer?

(M.G., The C. of L.:411)

Dan Ford, who is a lawyer, is Scott's former partner. Notwithstanding a number of obstacles which might ruin his career, Dan has decided to defend a black woman who is most probably a murderer. The eye contact of the speakers implicitly evokes negative emotive impact: Scott silently reproaches his partner for wrong behaviour.

The analysis of the emotive aspect of speech has enabled us to conclude that the mutually shared emotional background knowledge, that is, the previous emotional experience of the interlocutors, intermingles with the cognitive elements of the mind and finds its way of expression through speech. Thus, the psychological predisposition (favourable or unfavourable) of the interlocutors in the actual communicative event can be motivated by their social roles, relationships (mother - child, grandmother - granddaughter, uncle - niece, teacher - pupil, employer - employee, close friends, spouses, etc.), or past emotional experience (affection, hatred, humiliation, anger, etc.). The positively or negatively inclined mind of the interlocutors enables them to co-interpret the intended emotive meaning properly, even without having traced any explicit verbal elements expressing emotive charge in speech. The following example illustrates that the emotional mind of the speaker may influence the interpretation of the speech event:

Dex looks at me intently. "It's been a while, hasn't it?" I feel a quickening of my pulse as I nod, hold his gaze. "Too long," I echo, identifying 
a nervous feeling in my stomach. It is the way I felt when I first met Dex, when I was so conscious of his good looks and vigilant not to fall for him. But after a while, he was just Dex, my friend. Safe ground. And then he became the boyfriend of my best friend. Even safer ground.

(G.E., S.B.:15)

The speakers obviously share certain positive emotions which becomes evident when the author describes their non-verbal behaviour: a quickening of pulse, a nervous feeling in the stomach, intent look. Dex's indirect expressive speech act, It's been a while, hasn't $i t$ ?, implies that his speech bears traces of emotive memory: he evaluates his interlocutor positively and yearns for the times spent with her. Trying to show that she feels the same way, she responds with an approval, attaching extra positive emotive emphasis to it with the help of the intensifying adverb too: Too long. Nonetheless, the fact that the heroine is in close relationship with Dex's girlfriend hinders the explicature of the positive emotions experienced by the interlocutors in the past and existing at the moment of speech.

The negative predisposition of the interlocutors also plays a role in the process of communication, and, as a result, the speakers are more inclined to process the verbal behaviour in a negative light of thought. For instance, suppose you have succeeded in a public speaking competition. A person, with whom you have previously been in tense negative relations and, therefore, share negative emotional background knowledge, approaches you in the hour of your success and performs an expressive speech act like: You are the best orator I have ever known. The act of praise bears no negative implicature in it; nevertheless, you are most likely to interpret it negatively, since your negative emotional memory will hint you that this speech act lacks the felicity condition of sincerity.

In the following example one of the speakers experiences negative emotions, but she is not willing to display them explicitly. Since she does not actually manage to suppress her disappointment and distress, her emotions become apparent on the suprasegmental level, through voice qualifiers:

"I want to talk to you."

"What about?" I make my voice icy.

"What's wrong?"

"Nothing's wrong," I say, wishing I could think of something pointed and vengeful. I have not had much practice being mean, but my voice must do the trick because Dex looks hurt.

$$
\text { (G.E., S.B., 2011:165) }
$$

The reader of the given stretch of discourse can feel some negative emotional predisposition between the speakers who have been close friends for quite a long time. The thing is that Dex is engaged to Rachel's best friend Darcy but, as he confesses, he admired Rachel in the past. The fact that Dex feels affection for Rachel but continues his romantic relationship with Darcy hurts Rachel, but she does not want to express her dis- 
appointment and anger explicitly because she does not want to be humiliated any further, she wants to save her face. However, since the strong emotions prevail Rachel's rational thinking, she does not manage to maintain cognitive control over them, and eventually, the emotional mind becomes evident through her voice. The author remarks that Rachel makes her voice icy, which indicates her anger, frustration and comes to prove that Rachel has certain negative predisposition towards her interlocutor and wants to disgrace him. Furthermore, the author's interpretations provide evidence for Rachel's communicative strategy. Rachel confesses that she has not had much practice being mean, but she is sure that Dex felt the negative tone of her voice and got offended. Thus, we can state that the negative emotive charge, certain overtones of indirect reproach can be expressed with the help of voice qualifiers.

As a matter of fact, certain verbal actions include the negative emotive component as part of their semantic structure. Hence the acts of threatening, cursing, reproaching, blaming imply negative emotional attitude of the speaker and indicate contradictory interaction mode. Let us take the act of reproach. In fact, there has always been the dilemma of mothers and mothers-in-law. We are quite sure that if one's mother criticizes her for not cleaning up the room, she will not take it too close to heart and will not get offended, whereas in case the same act of reproach is performed by the mother-in-law, the daughter-in-law will probably get offended and seek for numerous negative implicatures in her speech. The following example comes to prove that the mutually shared emotional background knowledge of the speakers and their positive or negative predispositions play an irreplaceable role in the decoding process:

"How did you get a pass?" Eisenstein was asking.

"Oh, the sergeant fixed me up with one," answered Fuselli mysteriously.

"You're in pretty good with the sergeant, ain't yer?" said Eisenstein.

Fuselli smiled deprecatingly.

(D.P., Th. S., 1960:101)

Obviously, Einstein has felt pretty jealous and envious of Fuselli for quite a long period of time. The experience of these negative emotions is verbalized in his speech as he criticizes Fuselli for being in good terms with the sergeant. The intensifying adjverb pretty modifying the adjective good adds negative emotive implicature to the disjunctive question: You're in pretty good with the sergeant, ain't yer?. Fuselli elicits a non-verbal response: his deprecating smile implies that he has inferred the negative emotional attitude of the interlocutor and deplores it.

Presumably, the implicit action of emotional memory in the process of verbal interaction can be compared to the so-called iceberg theory proposed by the famous American writer E. Hemingway (Hemingway 1963:182). Iceberg theory, which refers to the author's style of writing, suggests that one eighth of the intended meaning should be expressed explicitly (the part of iceberg which is above the water), the remaining seven eighth (the part of iceberg which is below the water) should be implied by the writer and guessed by the reader. We think that since speakers, like writers, are creators of speech, 
this theory might be adaptable to spoken language as well: the words portray images; the speakers' emotions are embodied in the images; the inner thoughts are embodied in the emotions expressed via verbal and non-verbal actions.

Actually, there is much more going on beneath the surface of actual verbal interaction than we could imagine. And it is, indeed, a very difficult task for each and every one of us to grasp the full range of speaker meaning and respond adequately. Furthermore, no doubt we are always influenced by our previous positive or negative emotional experience which is embodied in our mental world as background emotional knowledge.

\section{References:}

1. Brandenburger, A. and Dekel, E. (1987) Common Knowledge with Probability 1. // Journal of Mathematical Economics, Vol. 16. North Holland: Elsevier.

2. Buzarov, V.V. (1998) Essentials of Conversational English Syntax. Moscow: Progress.

3. Dijk, T.A. van; W. Kintsch (1977) Cognitive Psychology and Discourse. // Current Trends in Text Linguistics. / Ed. by W.U. Dressier. Berlin, New York: de Gruyter.

4. Gilbert, M. (1989) On Social Facts. New York, London: TJ Press Ltd.

5. Grice, H.P. (1975) Logic and Conversation. // Syntax and Semantics. / Ed. by P. Cole \& J. Morgan, Vol. 3. New York: Academic Press.

6. Hemingway, E. (1963) Death in the Afternoon. London: Cape.

7. Hume, D. (2001) A Treatise of Human Nature. Oxford: Oxford University Press.

8. Jaggar, A.M. (June 1989) Love and Knowledge. // Emotion in Feminist Epistemology from Inquiry: An Interdisciplinary Journal of Philosophy and in Gender/Body/Knowledge with Susan R. Bordo. New Burnswick, N.J.: Rutgers University Press.

9. Locke, J. (1969) An Essay Concerning Human Understanding. Oxford: Clarendon Press.

10. Murray, E.J. (1964) Motivation and Emotion. New Jersey: Prentice-Hall, Inc.

11. Paronyan, Sh. (2005) Aspects of Salience in Phatic Tokens. // Armenian Folia Anglistika, International Journal of English Studies, N 1. / Ed. by S. Gasparyan et al. Yerevan: Lusakn.

12. Paronyan, Sh. (2009) On the Linguistic Expression of Uncertainty through Hesitation Markers in Conflict Talk in English. // Vesnik Kharkovskogo nacionalnogo universiteta im. V.N. Karazina, N 866, Kharkov.

13. Paronyan, Sh., Rostomyan, A. (2011) On the Interrelation between Cognitive and Emotional Minds in Speech. // Armenian Folia Anglistika, International Journal of English Studies, N 1-2(8). / Ed. by S. Gasparyan et al. Yerevan: Lusakn.

14. Paronyan, Sh. (2011) Lezvachanachoghutyun yev diskurs. Yerevan: YSU Press.

15. Rostomyan, A. (2009) Means of Expressing Emotive Emphasis in Conversational English. // Foreign Languages in Armenia, N 10. Yerevan: YSU Press.

16. Searle, J.R. (1969) Speech Acts: An Essay in The Philosophy of Language. 
Cambridge: Cambridge University Press.

17. Verschueren, S. (1999) Understanding Pragmatics. London, New York: Arnold.

\section{Sources of Data:}

1. Dos Passos, J. (1921) Three Soldiers. New York: Modern Library.

2. Dos Passos, J. (1960) U.S.A. Trilogy (The $42^{\text {nd }}$ Parallel, Nineteen Nineteen, The Big Money). Boston: Houghton Mifflin.

3. Gimenez, M. (2007) The Colour of Law. London: Sphere.

4. Giffin, E. (2011) Something Borrowed. London: Arrow Books.

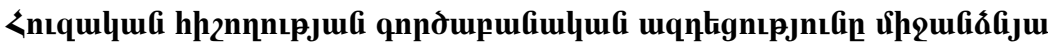 un|uhupuptipntpjnıtifitph ı|рu}

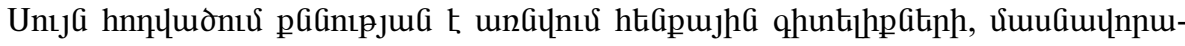

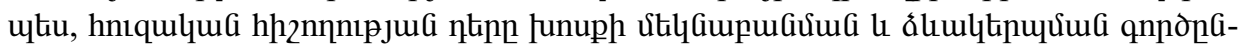

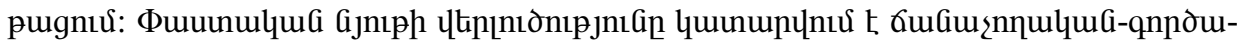

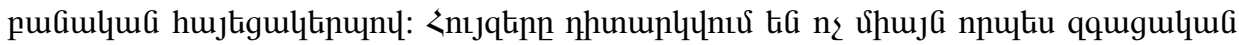

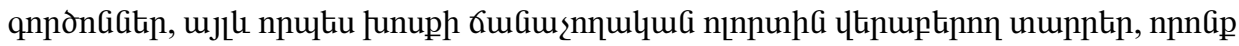

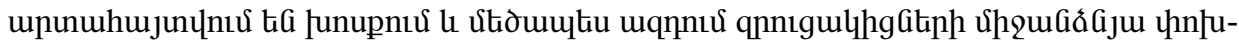
hupuptinnıpjntGiitiph цnu: 